\title{
Varieties of Power
}

\author{
Jesse M. Mulder ${ }^{1}$
}

Received: 25 November 2019/ Accepted: 28 March 2020 / Published online: 9 April 2020

(c) The Author(s) 2020

\begin{abstract}
Power enthusiasts are engaged in two projects: (1) developing a decent metaphysical account of powers, and (2) applying that account in order to make progress on various other philosophical issues, ranging from narrowly related topics such as causality to further removed ones such as free will, reasoning, or perception. I argue that an intermediate step may be taken, one that explores 'varieties of power' while still staying within the realm of (1), of 'pure' powers metaphysics. Taking this intermediate step provides a much more interesting basis for those involved in project (2), 'applied' powers metaphysics. I articulate four such varieties of power by exploring various dimensions in which the explanatory profile of a power can be extended. I then briefly survey how these relate to various further metaphysical issues.
\end{abstract}

Keywords Change - Consciousness · Explanation · Life · Power · Rationality · Thought

The metaphysical debate on powers is largely circling around questions concerning the correct characterization of powers, on how they are related to their manifestations, and on which place they occupy in the ontological catalogue of reality. ${ }^{1}$ Additionally, there are various attempts to make use of a powers

\footnotetext{
${ }^{1}$ See, e.g., Martin (1994, 1997), Mumford (1998), Ellis (2001, 2002), Molnar (2003), Williams (2019) and the essays in Marmodoro (2010). I should note, however, that these writers are of course interested also in applications of the powers idea to other metaphysical issues.
}

Jesse M. Mulder

j.m.mulder@uu.nl

1 Department of Philosophy and Religious Studies, Utrecht University, Janskerkhof 13, 3512BL Utrecht, The Netherlands 
metaphysics in other contexts - not only for the obviously related topics of causality and laws of nature, but also for, e.g., free will, perception, agency, etc. ${ }^{2}$ Now, there is an area of philosophical reflection on powers lying in between these two discussions_-between 'pure' and 'applied' philosophy of powers - that has, as far as I know, not received much attention. It departs from the-metaphysically clarified-generic concept of a power, and then considers various articulations of this concept. In other words, it considers 'varieties of power'. It does not yet take the step towards inquiring into this or that specific power: it stays on the 'pure' level of metaphysical or a priori inquiry into powers. Yet if the concept of power admits of such articulation into metaphysically distinct varieties, this is bound to be helpful for those seeking to apply the powers idea to this or that particular case. Instead of having to work with the very abstract, generic idea of a power, they may employ a more specific one that better suits their purposes from the start. ${ }^{3} \mathrm{I}$ will argue that there indeed are different varieties of power-four, to be precise-by developing them from the generic power concept. And it will transpire that these varieties of power are indeed interestingly related to a corresponding variety of metaphysical issues.

The plan is as follows. First, in Sect. 1 I set out my favorite generic conception of power (which is inspired, largely, by Rödl's (2012) account). Obviously, to get my project started I need some such generic conception, but I should stress that it is not my aim here to make a case for the conception to be presented against alternatives (although if it shows itself to be fruitful in my analysis, in the way in which it gives rise to varieties of power, that may count in its favor). Then, in Sect. 2 I develop the varieties of power that this generic conception of power gives rise to. Finally, in Sect. 3 I very briefly survey how these varieties of power are linked to a corresponding variety of metaphysical themes and theses.

\footnotetext{
2 See, e.g., Mumford (2004) and Lowe (2006) on laws of nature; Mumford and Anjum (2011) and Williams (2019) on causation; Heil (2003, 2012) on perception and consciousness; Lowe (2008) and Steward (2012) on agency; and Groff (2019) on free will. See also the essays in Groff and Greco (2013). Again, I should note that most of these authors are interested in more than just one application of the powers idea, and of course also in the metaphysics of powers as such.

${ }^{3}$ In fact, something like this is already happening, most notably amongst those applying the powers idea to issues related to human (or animal) agency. There, one frequently finds the claim that our power to act is a 'two-way power' (see, e.g., Lowe (2008), Steward (2012), or that it is a 'second-order power' (e.g., Groff (2019). Usually it remains unclear whether this is thought to be a genuine variety of power in my sense or rather just an interesting characteristic of a power that is, qua being a power, no different from other powers (in the same sense in which, e.g., powers whose manifestation tends to result in their own stimulus conditions may be thought interesting enough to deserve separate philosophical attention-see also Sect. 2 below).-There are exceptions: e.g., Kern (2017, esp. Ch. 6) develops an account of 'rational capacities' that marks them off from other powers as, indeed, a genuine variety of power. And Van Miltenburg and Ometto (2018) similarly develop a conception of the power to act that is, in fact, fully in line with that touched upon below in this article. Further references to related work will be given at the appropriate place in the discussion below.
} 


\section{The Generic Power Concept}

Often, the motivation for embracing a powers metaphysics lies in dissatisfaction with the Humean approach that has long been orthodoxy among analytic philosophers. Humeanism knows only of a large mosaic of particular matters of fact involving nothing but categorical properties, and attempts to account for generality in terms of regularity, that is, in terms of quantification over such particular matters of fact. ${ }^{4}$ Now, one important complaint is that such quantificational generality is explanatorily impotent: no particular matter of fact is explained by a generalization that merely summarizes, amongst other things, that very matter of fact. The switch to powers should make a difference here: it should not take what holds generally (i.e., what explanation depends on) to consist, ultimately, in regularities, in summaries of mere particular matters of occurrent fact. Nor does the defender of powers rest content with the addition of necessitating links between categorical properties on the general level, as certain rival anti-Humean views have it. $^{5}$ Instead, a powers metaphysics takes it that something general is somehow present in certain particular matters of fact themselves-in other words, it claims that powers are somehow present, or become 'manifest', in their manifestations. A power is thus 'something general' in at least the following sense: it can show itself in indefinitely many manifestations. (I will return to this idea of something general being present in the manifestation of a power below.)

Having thus introduced the notion of power by highlighting its significance, in contrast to rival metaphysical frameworks, let me sketch, in some detail, the generic conception of power on which my attempt at articulating varieties thereof depends. I will assume that powers are to be distinguished from states (my term for 'categorical properties'), and I will assume that both are borne by substances. Now, powers differ from states in that they are 'invisible': they do not show themselves directly but only in their manifestations. And that indicates, as I remarked, that they embody a certain generality, which in turn can be exploited in explanations of particular happenings (viz., their manifestations). As is standardly assumed, powers manifest in certain circumstances: these are regularly called their 'stimulus conditions'. So, when the bearer of a certain power finds itself in the proper circumstances, it will manifest that power. ${ }^{6}$ But what kind of entities are these manifestations?

Is a manifestation, perhaps, a state? No: the coming to be of that state may be thought to be the manifestation of a power, but the state does not point beyond itself, so to speak. Donald Trump has the power to turn red upon agitation: where this

\footnotetext{
${ }^{4}$ In Mulder (2018), I critically trace out this fundamental Humean idea of a 'mosaic of matters of fact' in much more detail.

5 This anti-Humean strand finds its origins in particular in Dretske (1977), Tooley (1977) and Armstrong (1978).

6 This characterization is not meant to exclude either 'spontaneous' powers, which may manifest regardless of the circumstances, or 'indecisive' powers, which may respond to the very same circumstances with different manifestations. (For instance, radioactive decay seems to occur spontaneously, although it can of course also be triggered; and certain quantum phenomena could be thought of as manifestations of 'indecisive' powers in this sense).
} 
power is manifested, it is not just the end result-his red face-that is important, but rather the transition towards this result: his face turning red. For similar reasons, the manifestation cannot be a substance: it may result in a substance, as when, upon my daughter's request, I exercise my power to make paper boats. So, the manifestation occupies a category of its own: the category of movements (happenings, changeswhat Aristotle called kinesis). ${ }^{7}$

Now, a movement is a peculiar entity. For a start, unlike states, movements $d o$ seem to point beyond themselves. Trump's face is turning red; I am making a paper boat: such statements report not just what is right here and now (the movement), they imply a continuation of sorts: they point towards the end result of the respective movement. A paradox appears to be lurking in this thought, on which much ink has already been spilled: a power may be triggered, and yet the resulting movement may fail to arrive at its end point. Trump's face might start showing red spots already here and there-but now a philosopher scares him to death with a horrifying contraption, thereby interrupting the reddening, the resulting state of his face being a pale white. The first steps of making a paper boat may have already been completed-but now my daughter runs off to play with her little sister, and I leave the project be. No paper boat results. ${ }^{8}$

This is a crucial feature of movements: wherever there is a movement, it is in progress, meaning that it is not yet completed. And whether or not it will eventually complete, reach its end, depends on whether or not something interferes. In the debate over this aspect of powers, the relation between movement and end is often not clarified. Instead, it is regularly assumed that the end of a power-what it is a power for-is simply identical to the manifestation. And it is under that assumption that incomplete movements such as the ones I just described are paradoxical: they cannot be manifestations of the corresponding powers, given that the ends of those powers are precisely not reached; yet they have to be manifestations of those powers, as they spring from the right circumstances ('stimulus conditions'). One distinctive advantage of the power concept I here propose to work with, which strictly distinguishes movement from end, is that it leaves no room for this paradox to arise: a power manifests in a movement; the end of the power is that which the movement brings forth when no interruption ensues. ${ }^{9}$ I should stress that this last

\footnotetext{
7 I take the term 'movement', which translates Aristotle's kinesis, from Rödl (2012). - Is this category the same as that of events? Not as events are usually understood, i.e., as individuated in terms of their temporal boundaries. On such a conception of events, these seem to correspond to completed movements (see below).-For a more detailed exposition of the philosophical understanding of time underlying my Rödl-inspired presentation of the generic power concept here, see Mulder (2017).

8 A detailed inventory of such cases has been constructed over the years, that differentiates between (at least) masks, antidotes, finks, and mimickers. On masks and antidotes, which involve special situations in which a certain disposition fails to manifest even though it is present, see, e.g., Johnston (1992), Bird (1998) and Choi (2003). On finks, which involve situations in which a disposition is taken away by the very same circumstances which are thought to trigger its manifestation, see for instance Martin (1994). On mimicking, which involves situations that make true the relevant counterfactuals even though the disposition is not present, see Lewis (1997).

9 This point has been forcefully made, at several occasions, by Elizabeth Anscombe-see, e.g., her (1971) and (1983). It has been picked up by, e.g., Thompson (2008, esp. Part II) and Rödl (2012, esp. Ch. $5)$.
} 
qualification is not a blank to be filled in by listing all possible interruptions. That is not needed: if the movement indeed reaches its end, there was no interruption; if it does not, there was an interruption. (This is so, as we will see shortly, because the end involved defines the movement as the movement that it is). It is in this way that the end of the movement bestows upon it that mysterious 'continuation', the peculiarly virtual presence of an end state that is not present yet, and may never become present at all (we will see in a moment in what this peculiar presence consists). The asymmetry between uninterrupted continuation and interruption is mirrored in an asymmetry of explanation: where Trump's power results in a red face, we may explain what happens by referring solely to that power (and the triggering circumstances), while if the reddening is interrupted, we must invoke the interrupting factor in our explanation as well. ${ }^{10}$

So far, we have, in our articulation of the concept of power, the following four ingredients: there is the bearer of the power-a substance; there are the circumstances in which the power is triggered; there is the movement in which the manifestation consists; there is the end result to which it leads when no interruption occurs. While the status of this final ingredient is still clouded at this point of our exposition, it is clear that the other ingredients involved-substance, movement, circumstances-are particular entities. If, as I promised, something general is somehow present in powers, we should thus expect to find it when we inquire into the way it incorporates its own end.

That is what we indeed find. For, if we want to identify a further particular entity as the end result to which the present movement is related, we find that there is nothing that can play that role. The end result is not present as something in the future, as it is still open whether or not that will materialize. But if it does eventually reach its end point, the end result will of course be a particular state (or substance) at a later point in time-so nothing else could play the role of the end result at an earlier moment. This shows the idea of a particular end to which movement relates to be incoherent. Hence, the end result is not present as a particular entity to which the movement is somehow related. Rather, it is presented as something general: I will follow Rödl in saying that it is present as the movement form (i.e., the kind of change, such as, for instance, reddening, or paper boat making). ${ }^{11}$ The thought is, thus, that every movement instantiates a movement form; and that all movements of the same form point towards the same general end. If a particular movement indeed reaches its end, this final state (or substance) will then be a particular instance of that general end.

Thus, powers include something general in at least two different ways. First, powers are general in that they can be manifested in indefinitely many movements - a power to redden manifests itself in indefinitely many episodes of reddening (whether completed or interrupted); a power to make paper boats manifests in indefinitely many episodes of paper boat making (whether completed or interrupted). And second, powers are powers for something: they specify a movement form, which in turn includes an end.

\footnotetext{
${ }^{10}$ Rödl (2012: esp. 203-4) provides a more detailed discussion of this explanatory asymmetry.

${ }^{11}$ See Rödl (2012: 152ff).
} 
But powers are also general in a third way, as can be seen from the routine sorts of power ascription statements one finds in the literature: 'glass is fragile', 'sugar is water-soluble', etc. In line with the terminology I have been borrowing from Rödl's (2012) exposition so far, let us say that powers fundamentally attach to substance forms. ${ }^{12}$ Even Trump's power to redden upon agitation, for instance, is of course not a peculiarly Trumpian power: it is something that (when properly qualified and precisified) belongs to humans. (While at this point the addition of substance forms perhaps seems inessential, it will turn out to play an important role in my articulation of varieties of power below.)

With these ingredients we can formulate typical power ascriptions as follows:

Power ascription: [Substance Form] have a power to instantiate [Movement Form] in [Circumstances].

The movement form determines the end result: that is why only the circumstances must be mentioned in power ascriptions. Different substance forms may have powers to instantiate the very same movement form in different circumstances-e.g., iron and water both have the power to melt, but under quite different circumstances.

Our ingredients also suffice for formulating typical power manifestation statements:

Power manifestation: A power manifests in a [Movement] that instantiates

[Movement Form], leading to [End Result] when no interruption occurs.

Table 1 presents the generic structure of power we have thus arrived at in a schematic way.

One might wonder: why is the power itself missing from Table 1? That is because I have approached the concept of power through what is central to that table: the concept of power manifestation-that is, the concept of movement. And that is not a mere personal preference: powers are, well, manifest only in their manifestations. If we understand power manifestation, we understand power. And hence, I suggest, we comprehend power if we comprehend the schema presented in Table 1.

This concludes my brief sketch of the generic account of power I favor. As I said at the beginning, it is not my aim to defend this account here against rival conceptions of power, let alone against power skeptics; I only wanted to circumscribe and motivate the account to a degree that is necessary for an

\footnotetext{
12 My use of 'form' in the phrases 'substance form' and 'movement form' is meant to indicate that these terms designate something general, as opposed to 'substance', 'movement', and 'circumstances', which, as I use them here, designate something particular. That is to say, an instance of 'movement form' is, for example, reddening, or paper boat making: these are themselves general. On the other hand, an instance of 'substance' is, for example, Donald Trump: a particular.-Although the question how my notion of substance form relates to the various conceptions of essence one finds in the contemporary literature, in the context of this essay I cannot do more than pointing out obvious affinities with, e.g., Wiggins's (2001) notion of sortal concepts, conjoined with his 'conceptual realism', with Lowe's $(2006,2009)$ notion of substantial kinds (though I would not accept his 'four-category ontology'), and with Fine's (1994) understanding of how essence relates to modality. See Mulder (2013) for an outline of my own account of essence.
} 
Table 1 The general structure of power

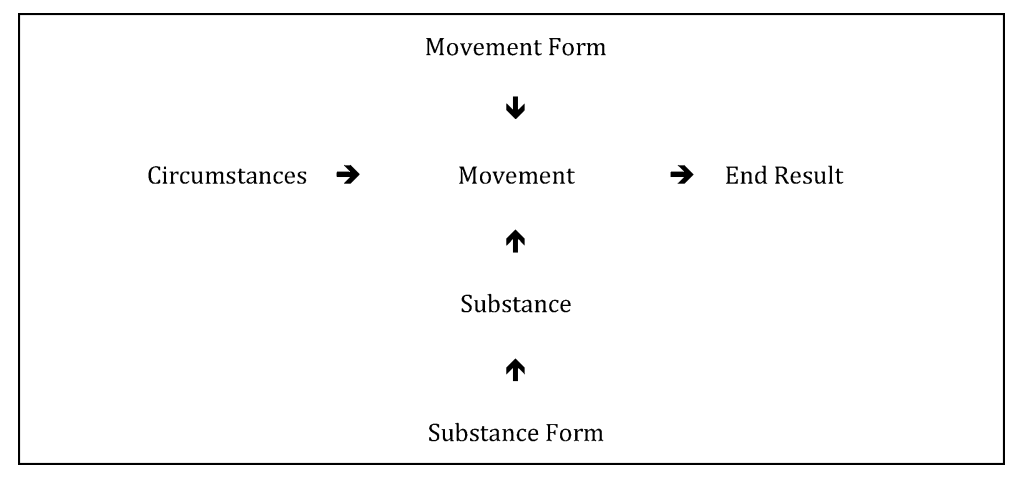

exploration of potential varieties of power on its basis. Let us therefore proceed to this exploration.

\section{Varieties of Power}

To start, we first need to make the following observation. A movement differs from a state in that it bears a peculiar relation to its prospective end result-which it does by virtue of the movement form it instantiates, we said. A state does not in this way point towards anything. That is why movements, and hence powers, are explanatory in a way in which states are not. (As we saw, Humeans think otherwise: they reject the entire category of power, and hence of movement, and take de facto regularities among states to be explanatory.) However, the generic concept of power is silent on whether or not movements have such peculiar explanatorily relevant relations to the other ingredients: to the circumstances that trigger the manifestation, to the individual substance that bears the relevant power, to the movement form, or to the substance form. This is bound to sound obscure at this point: what could such 'peculiar explanatorily relevant relations' consist in? Yet, as we will now see, this is precisely where our generic power concept leaves room for articulation into several varieties of power.

Let us call powers that are adequately characterized, metaphysically speaking, by our generic power concept level-0 powers. A typical example of a substance form that comes with such level-0 powers is water: it has the power to freeze, to evaporate, to dissolve various kinds of stuff, etc. Whenever water is put in the right kinds of circumstances, it will manifest those powers, resulting in movements of the corresponding movement forms: freezings, evaporatings, dissolvings. While in progress, such movements can usually be interfered with or stopped, e.g., if the circumstances are appropriately altered.

Now, although once water is engaged in such movements, the relevant end result is already on the horizon (being fully frozen, fully evaporated, having reached saturation or having fully dissolved the relevant stuff), water simply has those powers without their manifestations thereby being 'on the horizon'. That is to say, 
although water will behave in accordance with its powers in any circumstance, it is completely indifferent as to which circumstances it will find itself in. To understand what water will do in any circumstance, we have to consult the powers that it has, but to understand the circumstances in which it finds itself, we must look elsewhere.

As far as the generic power notion is concerned, this need not be the case. There could be powers which are such that they are had only when they find occasion to manifest. If such a power manifests, it will not be necessary to point out that the proper circumstances happened to occur, for that is in turn explained by the fact that the substance in question has the relevant power.

The relation between the presence of the power and the occurrence of the right circumstances will then be similar to that between movement and end result: just as, in the latter case, the end result will come about unless something interferes, so, in the former case, the relevant circumstances will come about unless something interferes. Thus, we could characterize this variety of power as follows: its manifestations not only explain its end result (when no interruption occurs), but also the coming about of the relevant circumstances. This can be the case if the circumstances in which the power manifests coincide with the end to which its manifestation leads when no interruption occurs. Such a power would be selftriggering, to coin a phrase. But powers of this variety may exhibit this structure also by forming a system: a substance can, for instance, have powers A-C such that its manifesting A leads to the proper circumstances for its manifesting B, which leads to the proper circumstances for its manifesting $\mathrm{C}$, which in turn leads to the proper circumstances for its manifesting A again.

We should be careful, however, to distinguish this situation from a case in which something has powers A'-C' which are such that, in the circumstances at hand, the manifestation of each merely happens to give rise to circumstances which trigger the next. For then it still holds that something may have such a trio of powers without ever running into the relevant circumstances leading to their cyclical manifestation. And that means that we would still have the fundamental 'indifference' towards whether or not the triggering conditions arise that is characteristic of level-0 powers. This doesn't yield a metaphysically different variety of power. What we are envisaging now is, rather, a situation in which the powers involved are essentially caught up in the described circle: the very existence of a substance with such powers consists in its manifesting those powers in the envisaged systematically linked way. So that it is in no way optional for those power to manifest or not.- Here we already see that to this new variety of power there corresponds a variety of substance form as well. Calling powers of our new variety level-1 powers, we may call the corresponding substance forms level-1 substance forms. Wherever such a level-1 substance form is instantiated, it is, through its self-supporting system of powers, keeping itself on the scene: every movement in which such a substance engages supports own existence by enabling it to exhibit more of its powers. In that sense, such a system of powers constitutes an internally teleological system- 'internally' teleological in the sense that the substance form in question can be considered its own end.

Having provided this brief and very abstract sketch, it will not be surprising that, in search for an example, we turn to the realm of the living. Take the system of 
powers that is characteristic of, e.g., an oak tree: it has the power to grow acorns, which in turn have the power to grow into oak trees (although this is of course a simplification that borders on the ridiculous), and it is obviously true that oak trees exist only when they manifest these powers as their typical life cycle prescribes (which is, we should recall, not to say that their powers' manifestations must always reach their ends). ${ }^{13}$

As Thompson (2008: 41) rightly remarks, a sign of the involvement of this sort of power is that it always makes sense, when studying a particular movement of the relevant kind, to ask What happens next? For level-0 substance forms and their level-0 powers such a question does not make sense: they are, as I put it earlier, indifferent as to the circumstances in which they find themselves, and so it only makes sense to ask what will happen next given certain circumstances. In the case of level-1 substance forms and their level-1 powers this question does make sense, and answering it will articulate some aspect of the system of powers in question. Think of the biologists' descriptions, often involving stylized graphic material, of 'the process of mitosis' or of 'the life cycle of the oak tree': each phase in those descriptions answers the 'what happens next?' question for the previous phase (at a certain level of resolution, of course).

Another variety of power can be discerned when we focus on the role the individual substance plays in its manifestations. Consider an individual pipistrelle bat, flapping through the nightly skies, chasing a particular moth. This is a movement, the manifestation of one of the powers characteristic of the pipistrelle's substance form: its power to hunt insects, let us say. And it is evident that this power forms a teleological system with other pipistrelle powers in the sense just described. However, this leaves out a crucial element. Consider some (unsaturated) water: any salt that is suitably brought into contact with it will be dissolved by it - the water has no preference for this or that bit of it, so to speak. Likewise, on a sunny day the oak tree's leaves are taking up the carbon dioxide that happens to be around as they engage in photosynthesis - the leaves have no preference for this bit or that bit of it. Water dissolves salt; oak trees take in carbon dioxide: these generic powerascribing statements explain the relevant particular movements. In the pipistrelle case, however, there is more to the explanatory story: although one can indeed say that this pipistrelle is chasing this moth because pipistrelles hunt insects, it is not a matter of course that the pipistrelle will strike whenever a moth is suitably present. First, it has to perceive the moth, and second, it has to desire it. In short: the individual pipistrelle must represent a specific target if it is to chase it. It is only through such representations that a movement like the chasing of a moth can be explained.

Now, both desire and perception are, in their turn, explained by the relevant substance form. Pipistrelles have the capacity to perceive-in particular, to detect

\footnotetext{
13 The understanding of life that is in the background here resonates with, e.g., the views of John Dupré, who comes to conclusions like the following: "the behavior of the part is to be explained by appeal to features of the whole" (Dupré 2010: 42), and: "a static cell", that is, one not engaged in processes, "is a dead cell" (Dupré 2013: 30). Interesting questions can be asked concerning how this understanding of life relates to evolutionary theory and other themes discussed in contemporary philosophy of biology. See Sect. 3 below, and Mulder (2016) for an in-depth discussion.
} 
insects; and they (generically) desire insects. Still, these powers are peculiar in that their manifestation in particular representings is required for the explanation of the sorts of movement we are trying to get into focus. Abstractly speaking, then, powers that manifest in movements of this sort, which I will call level-2 powers, differ from level-0 and level-1 powers as follows: in the level-0 and level-1 case, the individual substance does not contribute anything to what happens over and above what its substance form dictates, while level-2 powers operate only through representations of specific targets by the specific animal. As Rödl (2016: 89) writes: the animal 'is an individual toward individuals.' (Here we find the beginnings of a conception of the specifically animal powers of perception and desire as not 'just another power', but rather as constitutive of a specific form of having powers. We return to this in Sect. 3 below.)

Let us call substance forms that are characterized by systems of powers including such that depend on representation in this way level-2 substance forms. A level-2 substance form not only comprises an internally teleological system of powers: it includes powers that operate through consciousness (perception, desire). Traditionally, such powers have been called powers of self-movement: movement that originates in the individual animal, by virtue of its representations. Notice that such self-movements simply form part of the teleologically unified life cycle of animals, in the same way in which level-1 movements form part of the teleologically unified life cycle of plants.

Let us now proceed to the final variety of power. We observed that a level-2 power manifests through representations by its bearer of some particular target (e.g., this moth). The pipistrelle's movement, its chasing a moth, is explained by noting that pipistrelles hunt for insects and that this pipistrelle desires this moth, which is present to its senses. In this level-2 articulation of the concept of power, the movement not only points towards its own end (which is what characterizes level-0 powers); it also explains why the relevant circumstances came about, as it forms part of a teleologically integrated system of powers (which is what characterizes level-1 powers); and it involves the individual substance itself, by virtue of that substance's individual consciousness, by virtue of its representations (which is what characterizes level-2 powers). Now, remembering the schema I provided at the end of the previous section, in Table 1, this leaves out the two elements that designate something general: movement form and substance form. How could these be involved other than simply as the general forms that are instantiated in a particular movement or substance respectively? Well, there is precisely one other 'place' in which the general may be present: in thought. ${ }^{14}$ Level-2 powers, we saw, depend on a consciousness of the particular: the pipistrelle's desire has this particular moth in view. It does not include a consciousness of the general: the pipistrelle is not

\footnotetext{
14 Although one might wonder whether this really is a different 'place'. Kimhi (2018) thinks not-the difference is, in his terminology, merely 'syncategorematic'.
} 
conscious of the movement form it is instantiating. ${ }^{15}$ Consciousness that is capable of thought is different: it is capable of representing the very movement form it is manifesting. In philosophy, the resulting phenomenon is usually called intentional action, of which Elizabeth Anscombe (1957) famously claimed that it is something we know 'without observation', or, as her analysis reveals, something we practically know, the content of a practical judgment. ${ }^{16}$

The new ingredient in level-3 powers is that the general is as such represented in the individual. So, if I make a paper boat, the explanation will not rest on a principle like 'humans make paper boats' (which is of dubious standing anyway). Rather, the movement will be explained by my individual representation of the movement form-that is, by my practical judgment Let's make a paper boat. The movement is of the relevant form because that form is represented in my practical judgmenteven if the movement fails to live up to that form (thus, even if my attempt at a paper boat fails miserably). Now, this is not the place to develop a full conception of practical thought or of intentional action; it is sufficient for my purposes to point out that our generic power concept admits of a variety that precisely fits intentional action, action performed by beings capable of representing the general as such-i.e., beings endowed with thought.

Still, we should point out one peculiarity in this regard. We saw that my making the paper boat is explained by my individual judgment that I should make one, not, as is the case for the other varieties of power we have surveyed, by something generic, such as 'humans make paper boats'. Yet I claimed, at the end of the previous section, that such generic statements report, precisely, powers. So one might wonder: which power am I manifesting as I am making the paper boat? It is not the power to make paper boats. It seems that we have to say the following: we humans have the power to act intentionally, which we can now gloss as the power to instantiate movement forms by thinking them practically. Another way of saying the same thing is this: humans have the power to do what they decide to do. This power is peculiar in that it simply has no content: it does not attach the human being to a particular movement form, but rather to movement form generally. Thus, there is only one such power. In order for this power to manifest, it must first settle on one or the other movement form. That is what a practical judgment does: it determines the power to act intentionally by providing it with content. Thus, the explanatory 'work' that is done by the general connection between substance form and movement form on the earlier varieties of power is here done by the individual in his/her practical judgment, and therefore in the movement itself.-Note that this gives quite determinate content to the idea of autonomy, or freedom.

\footnotetext{
15 This characteristic extends: the pipistrelle is, in its perception of the moth, conscious of the moth, but not of the moth as a moth. Similarly, it is not conscious of its perception as perception, not conscious of its desire as desire. These 'as'-modifiers signify the relevant general concept, and concepts are the topic of a consciousness capable of thought. (This is not to deny that the pipistrelle treats moths differently from other kinds of nightly insects. The point is that this differential treatment does not rest on a comprehension of the relevant general concept.).

${ }^{16}$ For a recent defense of such an Anscombean understanding of intentional action that is in line with the present powers-related explorations, see Van Miltenburg and Ometto (2018).
} 
So far, we have seen that movements instantiating the level-3 power (now in singular) involve a peculiar relation to the movement form in question: it is represented in thought. But what about the substance form? I cannot develop the answer to this question here adequately, so an all too brief gesture as to its relation to the level-3 power will have to suffice. A level-3 substance form will be characterized by the power of thought. And that is to say that its instances will be capable of thinking their own substance form. This is, in fact, what happens in each and every practical judgment we make: in judging we always know ourselves to be judging, there is never any question as to whether it is judging that we do. And that means that in each act of our power to think we understand ourselves as beings capable of thought. There can be only one such substance form: it is that form whose instantiations are knowledge of that very form.- So much for my hopelessly inadequate gesture towards the level-3 substance form and its place with respect to the level-3 power. ${ }^{17}$

Perhaps an illustration helps to see what this gesture gestures towards. I am writing a paper on powers: this is a manifestation of my power to act, which takes the shape that it does-that of paper-writing, as opposed to, say, paper-boatmaking-not on account of external circumstances, nor on account of the fact that I am a substance of the kind that writes papers, but only on account of the fact that this is the determination that I give my generic power to act. That is why my action $i$ my consciousness of that very action. Intentional action is "a thought that is a movement", as Rödl says (2007, p. 19). Moreover, the content I am attempting to formulate in this paper illustrates the universality of the capacity of thought that is involved in this very activity. Thinking through the varieties of power, we realize that thought, the level-3 power, encompasses the whole range. It is not just a further rung on the ladder of powers, but rather unifies the whole ladder.

Let us sum up the four varieties of power that my inquiry yielded:

Level-O powers, or inanimate powers, conform to the generic schema I provided in Table 1. A level-0 movement displays the peculiar explanatory relation towards its end result that is characteristic of the very idea of a power, as it gives rise to the distinction between completion and interruption, and thus gives content to the idea that movements progress.

Level-1 powers, or animate powers, manifest in movements that display an additional explanatory relation: the power itself explains why the proper circumstances for the manifestation to come about arise. Level-1 powers form internally teleological systems whose unity is the corresponding level-1 substance form.

Level-2 powers, or conscious powers, manifest in movements that display yet another explanatory dimension: their manifestation rests on the individual substance representing a suitable target (by perception and desire). Level-2 powers form internally teleological systems that operate through consciousness; their unity is the corresponding level-2 substance form.

\footnotetext{
17 What I am gesturing towards with these sketchy remarks on the level-3 power has affinities with the understanding of thought recently revived, in different ways, by Rödl (2018) and Kimhi (2018).
} 
Level-3 powers, or self-conscious powers, manifest in movements for which yet another explanatory dimension enters the picture: their manifestation rests on the individual substance representing the movement form in question. There is only one level-3 power: the power to do what one represents. It is peculiar in that it does not include any specific movement form: that is precisely what the individual's representation provides.

Before turning to some further metaphysical reflections, let us look back at our method. We observed that what is distinctive of the generic power concept is the peculiar explanatory connection between a movement and its end. This generic power concept does not include any further peculiar explanatory relations, yet it does include ingredients that could figure in such relations (circumstances, substance, movement form, substance form). We looked at those ingredients in turn, and discovered that new varieties of power can be articulated by asking what sort of explanatory role these further ingredients may play. It is in this way that we arrived at level-1 powers, where the circumstances are drawn into the explanatory nexus; at level-2 powers, where the individual substance is drawn into the explanatory nexus; and at the level-3 power, where the movement form (and substance form) are drawn into the explanatory nexus. ${ }^{18}$ Thus articulating the varieties of power, it has become clear that the more one draws into the explanatory nexus, the more one is confronted with increasingly complex metaphysical issuesand the likelier it is, therefore, for the resulting variety of power to be found controversial. Luckily, my aim here has simply been to introduce these varieties of power, not to defend all of them. The latter would, I take it, require showing how each variety of power of necessity gives rise to the next, and that is not what I have been doing in this paper.

\section{Some Metaphysical Reflections}

One may endorse level-0 powers but reject all higher-level powers - the result will then be likely to be called a form of physicalism, or mechanism. One may in addition also endorse level-1 powers but reject higher-level powers, or endorse level-2 powers as well, but still reject the level-3 power. The pattern is familiar: these views are all, more or less, reductionist in character, as they are committed to conceiving of movements that appear to be higher-level in character as 'really'

\footnotetext{
18 Abstractly speaking, one might wonder why we have to draw in the aspects of the generic power notion in this order. Answers can be found to such questions - for instance: level-2 powers involve the individual animal, with its perceptions and desires, in the explanatory nexus; the triggering circumstances must here be represented in those perceptions and desires, and are thus implicitly already drawn into the life of this animal. Thus, the level-2 involvement of the individual substance implies the level-1 involvement of the triggering circumstances.-For reasons of scope, I cannot elaborate on this here for all the elements of the generic power notion.
} 
being only level-0 (or -1, or -2) in character. ${ }^{19}$ A first observation we can make as to the metaphysical import of the varieties of power developed above is, therefore, that they may provide valuable resources for those wishing to defend some form of metaphysical anti-reductionism. ${ }^{20}$

Now, what is it exactly that an anti-reductionist would be accepting an antireductionist account of, if she insists on the metaphysical reality of level-1, -2 or -3 powers? From my sketch of the varieties of power, it has become evident that these do not stand on their own: with level-1 powers come level-1 substance forms, and it is clear that these are what are often called life forms (e.g., Thompson 2008). More generally, endorsing level-1 powers is endorsing a distinctly metaphysical conception of life. Life is, then, not an empirical concept, but an a priori one. And the same holds 'higher up the ladder': accepting level-2 powers amounts to endorsing a distinctly metaphysical conception of the animal, and accepting the level-3 power amounts, as I have tried to suggest, to endorsing a distinctly metaphysical conception of ourselves as beings capable of thought.

Such 'distinctly metaphysical' conceptions can be thought of as formal concepts, or categories: the concept of life, used in this sense, does not delineate a manifold of substances - the living ones-by listing states and level-0 powers that differentiate those that live from those that don't (as one might, e.g., give such an account of metals, or of fermions). Rather, the concept of life designates a form of being: a form of being that maintains itself by implementing a teleologically unified system of level-1 powers. Likewise, the idea of a level-1 power, of a life-power, does not distinguish the movements of living things from those of other things in the way in which one might, say, distinguish among level-0 powers-powers to roll, powers to melt, etc. Rather, the idea of a life-power designates a form of power. Thus, a defender of level-1 powers could argue that the error made by those embracing a 'mechanistic' understanding of life lies precisely in that they try to capture a formal difference in terms of level-0 content. ${ }^{21}$-Spelling the resulting understanding of life out in more detail than we have done in the above would get us involved deeply in the metaphysics of life; doing so would confront us with hard questions concerning 'biological essentialism', a non-reductionist understanding of evolution, the relation between level-0 and level-1 powers, etc. ${ }^{22}$

Moving now to level-2 powers, it would be interesting to consider what accepting these as 'metaphysically fundamental' would mean for the contemporary discussion on consciousness: after all, if one accepts level-2 powers, consciousness turns out to

\footnotetext{
19 Perhaps some are convinced, through reflections of an action-theoretic nature, to embrace the level-3 power, while being skeptical of level-2 (or even of level-1) powers. I think an argument can be developed to the effect that level-3 powers already commit one to the sorts of features that define level-2 and level-1 powers, but I will not do so here. (Such an argument would make sense of Aristotle's approach to understanding level-3 phenomena through level-1 and level-2 phenomena in his De Anima-see, e.g., Haase (2013) and Gobsch (2017) for interesting explorations in this direction.).

${ }^{20}$ I have tried to defend an anti-reductionist take on life, using resources such as those developed here, in Mulder (2016).

21 At times, John Dupré seems to be making this point, albeit couched rather vaguely in terms of 'downward causation' and the like-see, e.g., Dupré (2012, 2013).

22 As mentioned earlier, I have taken up some of those challenges in Mulder (2016).
} 
be a formal concept in the sense just outlined. Perhaps the puzzlement about 'qualitative consciousness' - the 'hard problem' - arises, fundamentally, out of a mistaken assumption: that consciousness is not a formal characteristic of level-2 substances, but should be understood in purely level-0 terms. More broadly, the defender of level-2 powers would have to clarify how the metaphysical distinction between plants (level-1) and animals (level-2) relates to the now-standard biological classification of the realm of the living into a rather different range of 'domains': eukaryotes, bacteria, and archaea. The first thing to note here would, of course, be that the biological classification rests on empirical criteria, while the metaphysical distinction does not, so that the two need not be rivals.

Finally, attempts to shed light on our specifically human capacities by invoking the idea of power will take on a radically different shape, depending on whether one has the generic powers idea in mind or rather its level-3 variety. Indeed, taking the latter as one's starting point for answering pressing questions about, e.g., free will, or reasoning, or agency, will already presuppose answering some of those very questions - as can be seen from the fact that I was already more or less forced to preliminarily formulate such answers in merely trying to outline the idea of a level-3 power.

One might find it strange that I started out, in this paper, from a somewhat idiosyncratic generic conception of power. E.g., it is unusual, to say the least, to explicate powers in terms of 'movement forms'. Doesn't this require much more argument than I gave? As I noted earlier, seeing how this conception of power gives rise to a metaphysically interesting variety of power concepts may itself at least speak in favor of taking the generic power concept I started out with seriously. But here I would like, in closing this article, to return to the consideration from which I started to develop the generic power concept in Sect. 1. We noted, there, that the motivation for discarding the Humean orthodoxy and embracing a powers metaphysics lies in dissatisfaction with the Humean approach: Humeanism knows only of particular matters of fact, and attempts to account for generality in terms of quantification over such particular matters of fact. Such quantificational generality is explanatorily impotent: no particular matter of fact is explained by a generalization that merely summarizes, amongst other things, that very particular matter of fact. The switch to powers should make a difference here: it should see the general at work in the particular, establishing connections between particulars. That is precisely what is true of particular movements: they connect their point of departure to their end result. Then the unfolding of what is happening right here and now (the movement) can be explained by reference to what happens in general (the movement form). Unless the metaphysics of powers starts with such a marriage of the particular with the general, it will not be able to free itself from the grip of Humeanism, with its assumption that all must be explained in terms of the particular as such. And if powers metaphysics indeed takes this thorough-going anti-Humean turn, then the road is opened for the sort of development of this power notion presented here in the guise of four varieties of power.

Acknowledgements I am grateful to Victor Gijsbers, Martin Lipman, Niels van Miltenburg, Thomas Müller, Dawa Ometto, John Pemberton and Antje Rumberg for their valuable comments on (earlier 
versions of) this paper and/or discussions on its topic, as well as to audiences at Utrecht University, the University of Amsterdam, and the University of Constance for engaging discussions concerning its main ideas.-This work was supported by the Dutch National Science Foundation (NWO) VENI Grant scheme, Grant Number 275-20-068.

Open Access This article is licensed under a Creative Commons Attribution 4.0 International License, which permits use, sharing, adaptation, distribution and reproduction in any medium or format, as long as you give appropriate credit to the original author(s) and the source, provide a link to the Creative Commons licence, and indicate if changes were made. The images or other third party material in this article are included in the article's Creative Commons licence, unless indicated otherwise in a credit line to the material. If material is not included in the article's Creative Commons licence and your intended use is not permitted by statutory regulation or exceeds the permitted use, you will need to obtain permission directly from the copyright holder. To view a copy of this licence, visit http:// creativecommons.org/licenses/by/4.0/.

\section{References}

Anscombe GEM (1957) Intention. Harvard University Press, Cambridge

Anscombe GEM (1971) Causality and determination. In: Anscombe GEM (ed) (1981) Collected philosophical papers volume 2: metaphysics and the philosophy of mind. Wiley-Blackwell, Oxford

Anscombe GEM (1983) The causation of action. In: Anscombe GEM (ed) (2005) Human life action and ethics. Imprint Academic, Exeter

Armstrong DM (1978) Universals and scientific realism volume 2: a theory of universals. Cambridge University Press, Cambridge

Bird A (1998) Dispositions and antidotes. Philos Q 48(191):227-234

Choi S (2003) Improving birds antidotes. Aust J Philos 81(4):573-580

Dretske FI (1977) Laws of nature. Philos Sci 44(2):248-268

Dupré J (2010) It is not possible to reduce biological explanations to explanations in chemistry and/or physics. In: Ayala F, Arp R (eds) Contemporary debates in philosophy of biology. Blackwell Publishing, Malden

Dupré J (2012) Processes of life: essays in the philosophy of biology. Oxford University Press, Oxford Dupré J (2013) Living causes. Arist Soc Proc 87(1):19-37

Ellis BD (2001) Scientific essentialism. Cambridge University Press, Cambridge

Ellis BD (2002) The philosophy of nature: a guide to the new essentialism. Acumen, Chesham

Fine K (1994) Essence and modality. Philos Perspect 8:1-16

Gobsch W (2017) Der Mensch als Widerspruch und absolutes Wissen. In: Kern A, Kietzmann C (eds) Selbstbewusstes Leben. Suhrkamp, Berlin

Groff R (2019) Sublating the free will problematic: powers agency and causal determination. Synthese 196(1):179-200

Groff R, Greco J (2013) Powers and capacities in philosophy: the new Aristotelianism. Routledge, New York

Haase M (2013) Life and mind. In: Khurana T (ed) The freedom of life: Hegelian perspectives. August Verlag, Berlin

Heil J (2003) From an ontological point of view. Clarendon Press, Oxford

Heil J (2012) The universe as we find it. Oxford University Press, New York

Johnston M (1992) How to speak of the colors. Philos Stud 68(3):221-263

Kern A (2017) Sources of knowledge. Translated by D Smyth. Harvard University Press, Cambridge

Kimhi I (2018) Thinking and being. Harvard University Press, Cambridge

Lewis DK (1997) Finkish dispositions. Philos Q 47(187):143-158

Lowe EJ (2006) The four-category ontology: a metaphysical foundation for natural science. Oxford University Press, New York

Lowe EJ (2008) Personal agency: the metaphysics of mind and action. Oxford University Press, New York 
Lowe EJ (2009) More kinds of being. Wiley-Blackwell, Malden

Marmodoro A (2010) The metaphysics of powers: their grounding and their manifestations. Routledge, New York

Martin CB (1994) Dispositions and conditionals. Philos Q 44(174):1-8

Martin CB (1997) On the need for properties: the road to pythagoreanism and back. Synthese 112(2):193-231

Molnar G (2003) Powers: a study in metaphysics. Oxford University Press, New York

Mulder JM (2013) The essentialist inference. Aust J Philos 91(4):755-769

Mulder JM (2016) A vital challenge to materialism. Philosophy 91(2):153-182

Mulder JM (2017) Two fundamentally different perspectives on time. Axiomathes 27(3):295-320

Mulder JM (2018) The limits of humeanism. Eur J Philos Sci 8(3):671-687

Mumford S (1998) Dispositions. Oxford University Press, New York

Mumford S (2004) Laws in nature. Routledge, New York

Mumford S, Anjum RL (2011) Getting causes from powers. Oxford University Press, New York

Rödl S (2007) Self-consciousness. Harvard University Press, Cambridge

Rödl S (2012) Categories of the temporal. Harvard University Press, Cambridge

Rödl S (2016) Education and autonomy. J Philos Educ 50(1):84-97

Rödl S (2018) Self-consciousness and objectivity. Harvard University Press, Cambridge

Steward H (2012) A metaphysics for freedom. Oxford University Press, Oxford

Thompson M (2008) Life and action. Harvard University Press, Cambridge

Tooley M (1977) The nature of laws. Can J Philos 7(4):667-698

Van Miltenburg N, Ometto D (2018) Free will and mental powers. Topoi. https://doi.org/10.1007/s11245$018-9615-8$ (in press)

Wiggins D (2001) Sameness and substance renewed. Cambridge University Press, Cambridge

Williams NE (2019) The powers metaphysic. Oxford University Press, Oxford

Publisher's Note Springer Nature remains neutral with regard to jurisdictional claims in published maps and institutional affiliations. 